\title{
Corrosion Inhibitive Potentials of some 2H-1-benzopyran- 2-one Derivatives- DFT Calculations
}

\author{
Oluwatoba Oyeneyin 1,*(i), Daniel Akerele ${ }^{1(\mathbb{D})}$, Nathanael Ojo ${ }^{2(\mathbb{D})}$, Ogunyemi Oderinlo ${ }^{3(\mathbb{C})}$ \\ 1 Theoretical and Computational Chemistry Unit, Department of Chemical Sciences Adekunle Ajasin University, Akungba- \\ Akoko, Ondo State, Nigeria; emmanueltoba90@gmail.com (O.O.), oluwatoba.oyeneyin@aaua.edu.ng (O.O.), \\ daniel.akerele@aaua.edu.ng (D.A.); \\ 2 Department of Chemistry, University of Ibadan, Ibadan, Nigeria; dammynath@yahoo.com (N.O.); \\ 3 Department of Chemistry, Federal University Otuoke, Bayelsa State, Nigeria; oderinlooo@ fuotuoke.edu.ng (O.O.); \\ * Correspondence: emmanueltoba90@gmail.com (O.O.), oluwatoba.oyeneyin@aaua.edu.ng (O.O.); \\ dammynath@yahoo.com (N.O.);

Received: 23.01.2021; Revised: 19.02.2021; Accepted: 21.02.2021; Published: 2.03.2021

\begin{abstract}
There is an increased demand for metals and alloys because of their use in household appliances and industrial machines. However, they react with the environment and are consequently prone to loss of strength and durability owing to corrosion. In a bid to eradicate or control this, the use of corrosion inhibitors has been employed. Quantum chemical calculations have been used to predict the corrosion inhibitive potentials of novel molecules and probe into their metals' surface mode of action. Density functional theory was employed here with a polar basis set, 6-31G(d), to investigate the corrosion inhibitive potentials of some $2 \mathrm{H}-1$ - benzopyran-2-ones derivatives via their electronic properties, global reactivity descriptors, electrostatic potential maps, and Fukui indices. The energy gaps follow the order: $\mathrm{c}>\mathrm{e}>\mathrm{a}>\mathrm{d}>\mathrm{b}>\mathrm{g}>\mathrm{f}>\mathrm{h}$, indicative that compounds $\mathrm{f}$ and h would effectively protect metals' surface against corrosion with the HOMO map essentially delocalized over the benzopyran-2-one moiety and the attached substituents while the LUMO plot shows a delocalization of the lowest vacant molecular orbitals over the entire benzopyran-2-one moiety. The asymmetric charge distribution on the inhibitors from the electrostatic potential maps indicates that each compound possesses reactive adsorption sites for bonding and back-bonding with the metal surface. The Mulliken charge distribution and the Fukui indices reveal that the adsorption of an inhibitor on a metal surface is not only via the heteroatoms like $\mathrm{O}, \mathrm{Cl}, \mathrm{Br}$, and $\mathrm{N}$. The contribution of carbon atoms as nucleophilic and electrophilic centers ensures effective interaction between a metal surface and the inhibitor and isolates the material from corroding environment.
\end{abstract}

Keywords: corrosion; organic corrosion inhibitors; 2h-1-benzopyran-2-ones; density functional theory; Fukui indices.

(C) 2021 by the authors. This article is an open-access article distributed under the terms and conditions of the Creative Commons Attribution (CC BY) license (https://creativecommons.org/licenses/by/4.0/).

\section{Introduction}

Metals corrode when they come in contact with oxygen, hydrogen, an electric current etc., from their surroundings, and they lose their form, shape, strength, and durability. Loss of lives and properties have been reported together with an increased production cost as some of the effects of corrosion [1]. Controlling corrosion has generated so much attention. Organic inhibitors are preferred to other classes of inhibitors due to their $\pi$-conjugated architecture, making for electrons' easy movement throughout their entire systems [2]. Organic compounds 
containing heteroatoms like $\mathrm{O}, \mathrm{N}$, and $\mathrm{S}$ have been reported for enhanced inhibitive potentials owing to the presence of lone pairs, which are readily available for bonding with metals $[1,3$, $4,5]$. Most organic compounds also have an electrophilic region in their systems that also accept an electron from the metal's orbitals (back-bonding) [4, 6, 7]. They adsorb on the surface of the metal and protect it from aggression.

2H-1-benzopyran-2-ones are a class of organic compounds that are commonly produced by various species of plants [8, 9] and a few fungi and bacteria [10]. Structurally, they are phenolic compounds composed of a benzene ring fused to $\alpha$-pyrone ring [9]. Several studies have established the pharmacological activities of 2H-1-benzopyran-2-one of both natural and synthetic origin [11,12 ]. Interest in applying this structural class of compounds is significantly increasing in many areas of material science, including corrosion inhibition, due to their inherent photophysical and electrochemical properties [13, 14]. In awareness of these properties and in continuation of our research efforts to identify organic compounds with corrosion inhibition properties $[3,4,15]$, herein we seek to investigate the corrosion inhibitive potentials of 2H-1-benzopyran-2-ones derivatives via DFT calculations. The 2H-1benzopyran-2-ones derivatives used in this study were recently reported by Gulati et al. [16].

\section{Materials and Methods}

\subsection{Computational details.}

The compounds (figure 1) were modeled and subjected to conformation search to obtain the most stable conformers using molecular mechanics force field followed by optimization using a restricted hybrid Hartree Fock-DFT self-consistent field calculation, Becke-3-LeeYang-Parr (B3LYP) with Pulay's direct inversion of the iterative sub-space and direct geometric minimization [17] and a polar basis set 6-31G(d) [18], all on an intel core i5-2520M laptop with $2.50 \mathrm{GHz}$ and 8.00GB RAM with Spartan 14 computational chemistry software [19]. The energies of the highest occupied molecular orbital (Еномо), lowest unoccupied molecular orbital (Elumo), energy band gap, Eg (eq. 1), ionization potential, I (eq. 2), electron affinity, $\mathrm{A}$ (eq. 3), chemical hardness, $\eta$ (eq. 4), chemical softness, $\delta$ (eq. 5), electronegativity $\chi$ (eq. 6), global electrophilicity (eq. 7), the fraction of electron transferred, $\Delta \mathrm{N}$ (eq. 8) were obtained. The Fukui parameters were calculated (eqs. 9-11).

$$
\begin{aligned}
& \mathrm{E}_{\mathrm{g}}=\mathrm{E}_{\text {LUMO }}-\mathrm{EHOMO} \\
& \mathrm{I}=- \text { Еномо } \\
& \mathrm{A}=-\mathrm{ELUMO}_{\text {LUMO }} \\
& \eta=\frac{E_{L U M O}-E_{H O M O}}{2} \\
& \delta=\frac{1}{\eta} \\
& \chi=-\frac{E_{L U M O}-E_{H O M O}}{2} \text { or } \quad \frac{I+A}{2} \quad 6 \\
& \begin{array}{ll}
\frac{\chi^{2}}{2 \eta} & 7
\end{array} \\
& \Delta \mathrm{N}=\frac{\chi_{F e}-\chi_{i n h}}{2\left(\eta_{F e}+\eta_{i n h}\right)} \quad 8
\end{aligned}
$$

Where $\chi_{\mathrm{Fe}}$ is the electronegativity of iron $(7.0 \mathrm{eV}), \chi_{\mathrm{inh}}$ is the electronegativity of the inhibitor molecule, $\eta_{\mathrm{Fe}}$ is the chemical hardness of iron $(0 \mathrm{eV})$, while $\eta_{\text {inh }}$ is the chemical hardness of the inhibitor molecules.

The Fukui parameters (eqs. 9-11) tell us which atom is electrophilic or nucleophilic by using Yao's dual descriptor. 
$f_{k}^{+}=\left[q_{k}(N+1)-q_{k}(N)\right]$ for nucleophilic attack

$f_{k}^{-}=\left[q_{k}(N)-q_{k}(N-1)\right]$ for electrophilic attack

$\Delta f_{k}(r)=f_{k}^{+}-f_{k}^{-}$

When the molecule accepts an electron, the charge on the atoms is defined by $\mathrm{q}_{\mathrm{k}}(\mathrm{N}+1)$. $\mathrm{q}_{\mathrm{k}}(\mathrm{N})$ defines the charges on the atoms in the molecules' neutral state, while $\mathrm{q}_{\mathrm{k}}(\mathrm{N}-1)$ is the charges on the atoms when the molecule loses an electron [20]. $\mathrm{F}_{\mathrm{k}}{ }^{+}$and $\mathrm{f}_{\mathrm{k}}{ }^{-}$are the nucleophilic and electrophilic Fukui functions, respectively.

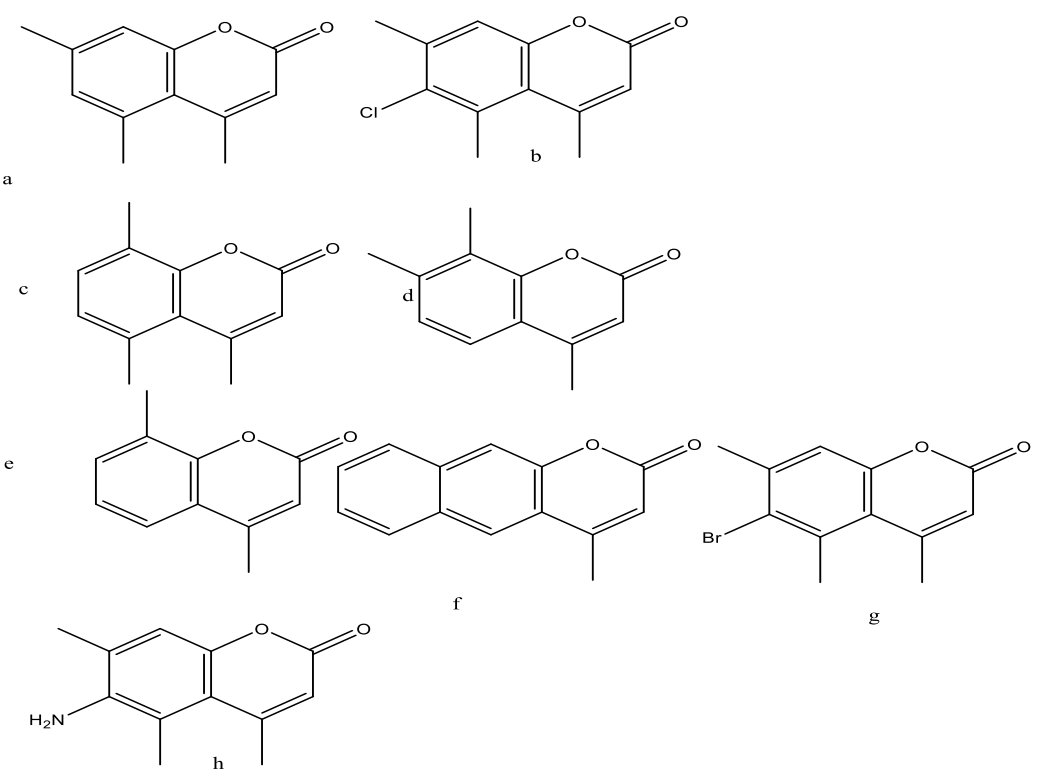

Figure 1. Structures of the molecules.

\section{Results and Discussion}

The results of the quantum chemical calculations on the corrosion inhibition potentials of the coumarin derivatives, a to $h$, are presented in Tables 1-9. The compounds are rich in heteroatoms and $\pi$-electrons, which may act as nucleophilic centers of adsorption and $\pi$ - $\pi$ stacking. Figures 1-17 show the 2-D structures, optimized structures, HOMO, LUMO, and electrostatic potential maps of a to $h$.

Table 1. Quantum chemical parameter of a-h.

\begin{tabular}{ccccccccccc}
\hline Molecules & $\mathbf{E}_{\text {Hомо }}(\mathbf{e V})$ & $\mathbf{E}_{\mathbf{L u m o}}(\mathbf{e V})$ & $\mathbf{E}_{\mathbf{g}}(\mathbf{e V})$ & $\mathbf{I}(\mathbf{e V})$ & $\mathbf{A}(\mathbf{e V})$ & $\boldsymbol{\eta}(\mathbf{e V})$ & $\delta\left(\mathbf{e V}^{\mathbf{- 1}}\right)$ & $\boldsymbol{\chi}(\mathbf{e V})$ & $\boldsymbol{\omega}(\mathbf{e V})$ & $\boldsymbol{\Delta} \mathbf{N}$ \\
\hline $\mathrm{a}$ & -6.20 & -1.58 & 4.62 & 6.20 & 1.58 & 2.31 & 0.43 & 3.89 & 3.28 & 0.67 \\
$\mathrm{~b}$ & -6.34 & -1.83 & 4.51 & 6.34 & 1.83 & 2.26 & 0.44 & 4.09 & 3.70 & 0.65 \\
$\mathrm{c}$ & -6.27 & -1.6 & 4.67 & 6.27 & 1.6 & 2.34 & 0.43 & 3.94 & 3.32 & 0.66 \\
$\mathrm{~d}$ & -6.21 & -1.6 & 4.61 & 6.21 & 1.6 & 2.31 & 0.43 & 3.91 & 3.31 & 0.67 \\
$\mathrm{e}$ & -6.32 & -1.66 & 4.66 & 6.32 & 1.66 & 2.33 & 0.43 & 3.99 & 3.42 & 0.66 \\
$\mathrm{f}$ & -6.02 & -2.04 & 3.98 & 6.02 & 2.04 & 1.99 & 0.50 & 4.03 & 4.08 & 0.75 \\
$\mathrm{~g}$ & -6.52 & -2.03 & 4.49 & 6.52 & 2.03 & 2.25 & 0.45 & 4.28 & 4.07 & 0.61 \\
$\mathrm{~h}$ & -5.44 & -1.47 & 3.97 & 5.44 & 1.47 & 1.99 & 0.50 & 3.46 & 3.01 & 0.89 \\
\hline
\end{tabular}

\subsection{Corrosion inhibition and frontier orbital energies.}

The anti-corrosion potential of a many-body system is significantly related to its molecular orbital energies. Table 1 shows the energy gap, energies of the highest occupied molecular orbital (Еномо), and lowest unoccupied molecular orbital (Elumo). High Eномо is related to the greater electron-donating potential of a corrosion inhibitor. The positional isomers a, c and d exhibit relatively high Еномо, indicating good electron-donating potential of the systems. Halide modification to the benzopyran-2-one moiety ( $b$ and $g$ ) at position 6 results 
in a remarkable stabilization of the highest filled molecular orbital. This implies that the halosubstituted derivatives possess the less electron-donating ability, which could be attributed to the halide and carbonyl's high electronegativity (and electron-withdrawing property) groups. Removal of a methyl group from e reduces the positive inductive effect experienced by the benzopyran-2-one. It possibly stabilizes the Еномо of the system relative to inhibitor $\mathrm{c}$. The

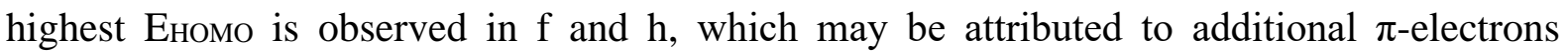
introduced by the attached phenyl ring and the electron-donating amino group, respectively. Materials with high Еномо have the excellent potential of pushing electrons into the low-lying vacant orbital of a corroding environment, thereby retarding the anodic process $[21,6]$.

Table 2. Selected calculated Fukui functions and Mulliken atomic charges of a.

\begin{tabular}{lllllll}
\hline Atoms & $\mathbf{q}_{\mathbf{k}}(\mathbf{N}+\mathbf{1})$ & $\mathbf{q}_{\mathbf{k}}$ & $\mathbf{q}_{\mathbf{k}}(\mathbf{N}-\mathbf{1})$ & $\mathbf{f}_{\mathbf{K}}^{+}$ & $\mathbf{f}_{\mathbf{K}}^{-}$ & -0.021 \\
\hline C1 & -0.273 & -0.243 & -0.222 & -0.03 & -0.009 \\
C2 & 0.308 & 0.317 & 0.37 & -0.009 & -0.053 & 0.044 \\
C3 & 0.033 & 0.026 & 0.047 & 0.007 & -0.021 & 0.028 \\
C4 & 0.088 & 0.117 & 0.143 & -0.029 & -0.026 & -0.003 \\
C5 & -0.261 & -0.246 & -0.209 & -0.015 & -0.037 & 0.022 \\
C6 & 0.186 & 0.199 & 0.211 & -0.013 & -0.012 & -0.001 \\
C7 & -0.526 & -0.535 & -0.55 & 0.009 & $\mathbf{0 . 0 1 5}$ & $-\mathbf{0 . 0 0 6}$ \\
C8 & -0.522 & -0.536 & -0.545 & $\mathbf{0 . 0 1 4}$ & 0.009 & $\mathbf{0 . 0 0 5}$ \\
C9 & 0.109 & 0.191 & 0.591 & -0.082 & -0.4 & 0.318 \\
C10 & -0.328 & -0.297 & -0.227 & -0.031 & -0.07 & 0.039 \\
C11 & -0.521 & -0.533 & -0.545 & 0.012 & 0.012 & 0 \\
C12 & 0.551 & 0.605 & 0.638 & -0.054 & -0.033 \\
O1 & -0.565 & -0.515 & -0.467 & -0.05 & -0.048 \\
O2 & -0.593 & -0.478 & -0.347 & -0.115 & -0.131 \\
\hline
\end{tabular}

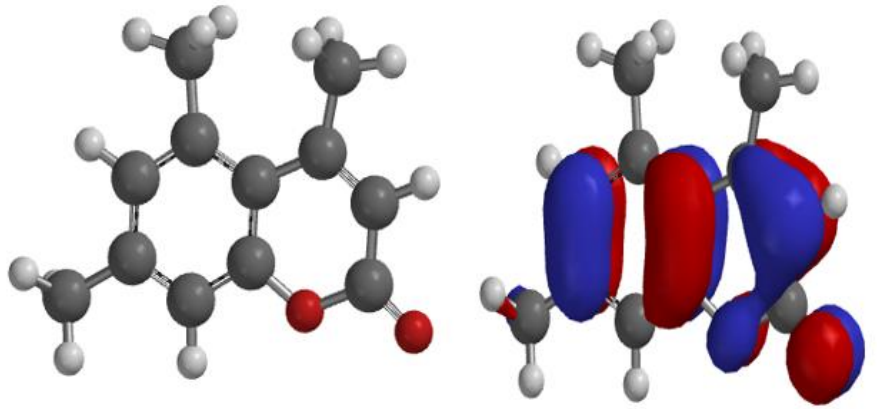

(a) (b)

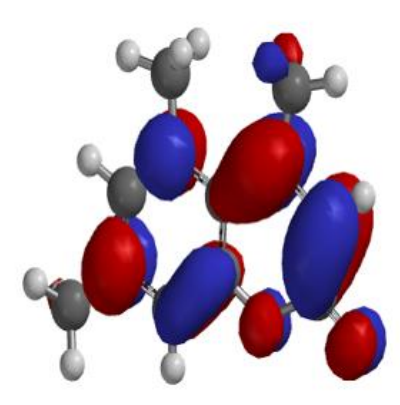

(c)

Figure 2. (a) Optimized structure of a, (b) HOMO map of a, and (c) LUMO map of a.
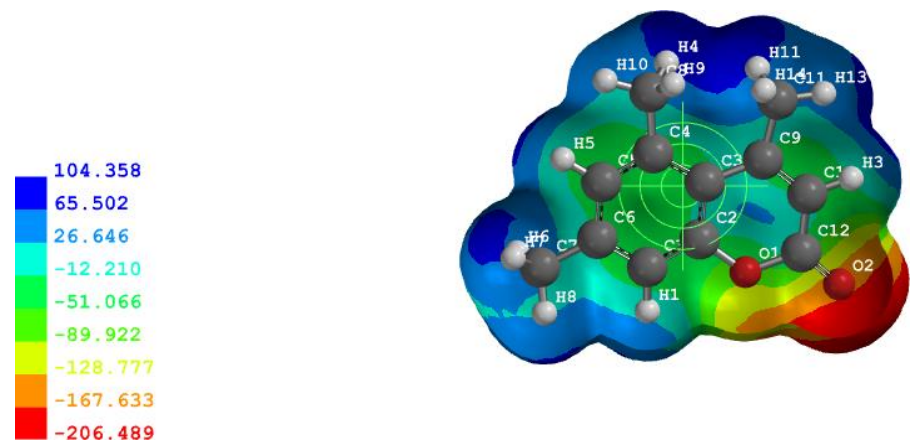

Figure 3. Electrostatic potential map of a. 


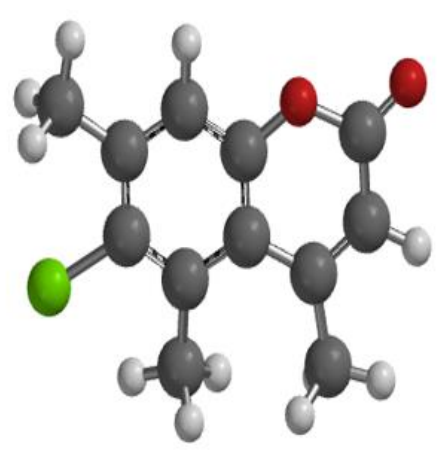

(a)

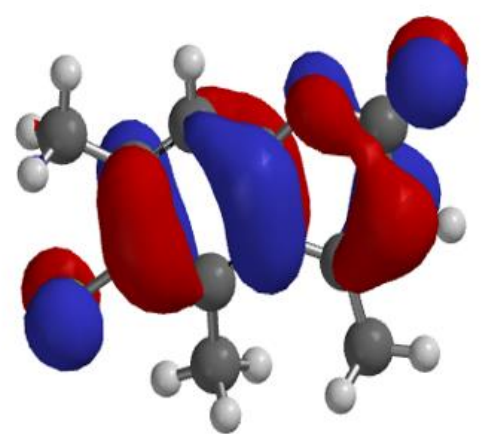

(b)

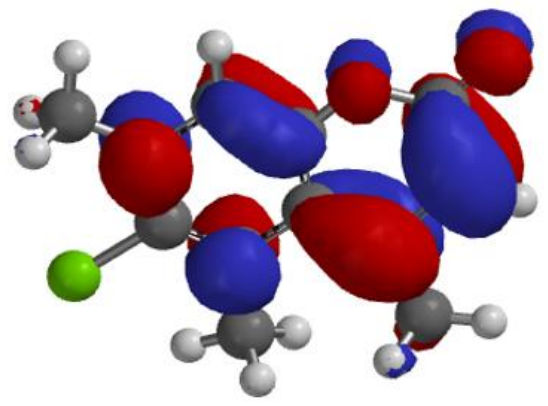

(c)

Figure 4. (a) Optimized structure of b, (b) HOMO map of b, and (c) LUMO map of b.
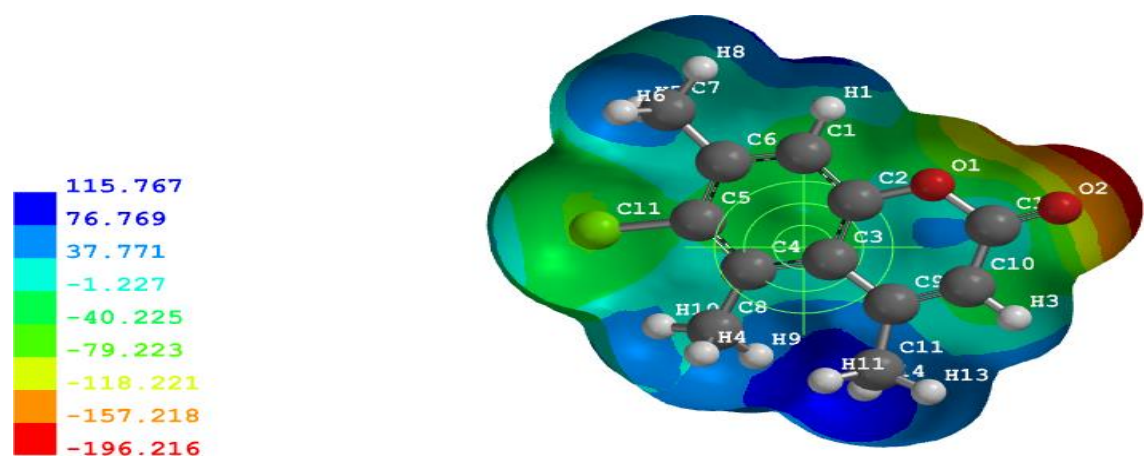

Figure 5. Electrostatic potential map of $b$.

Furthermore, the LUMO's stabilization enhances the corrosion inhibitor's electronaccepting potential, which invariably facilitates interactions between the inhibitor and the corroding material. This interaction promotes the isolation of the corroding material from the corroding environment. Although the least vacant orbital energies of the corrosion mitigators do not follow a particular trend with the Еномо, the coumarin derivative with additional phenyl moiety (f) displays the greatest stabilization. Also notable is the low-lying LUMO of the bromo-substituted benzopyran-2-one (g).

Moreover, a low energy gap has been associated with chemical reactivity, molecular softness, kinetic instability, and good corrosion inhibition potentials [22-24]. The compounds present a low energy gap, which implies that they are potential anti-corrosion materials. The energy gaps follow the order: $c>e>a>d>b>g>f>h$ which indicates that the compounds $\mathrm{f}$ and $\mathrm{h}$ would offer effective anti-corrosion protection. The remarkably low energy gaps of compounds $\mathrm{f}$ and $\mathrm{h}$ could be attributed to the relative destabilization of the HOMO and/or stabilization of LUMO.

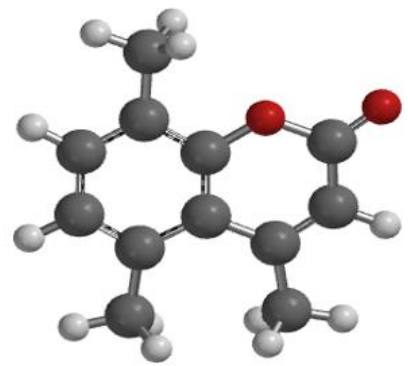

(a)

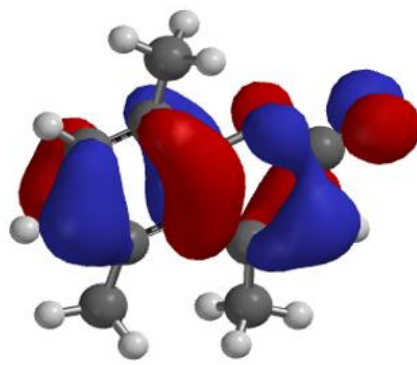

(b)

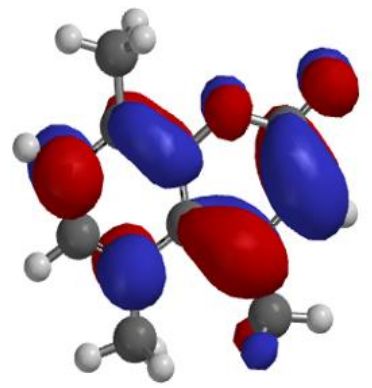

(c)

Figure 6. (a) Optimized structure of c, (b) HOMO map of c and (c) LUMO map of c. 

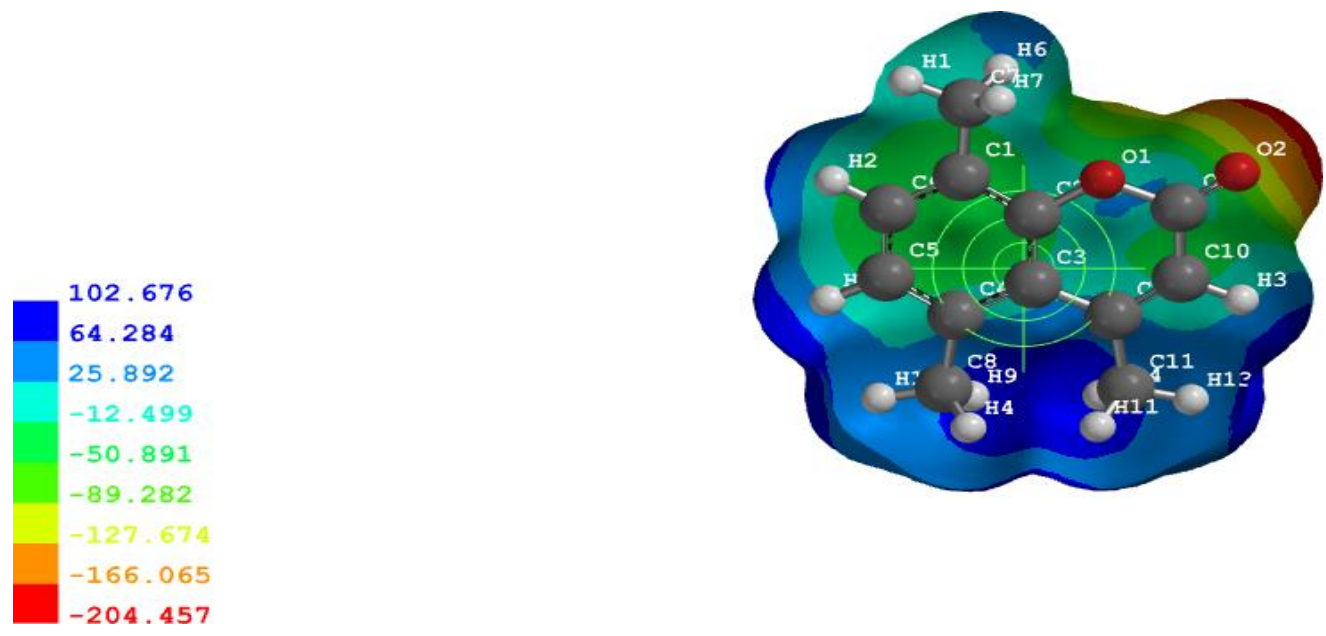

Figure 7. Electrostatic potential map of c.

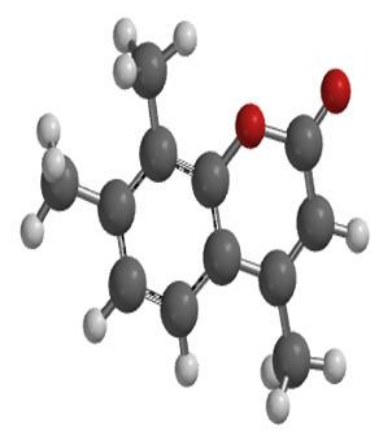

(a)

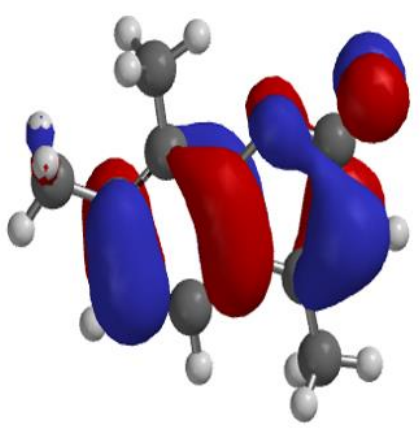

(b)

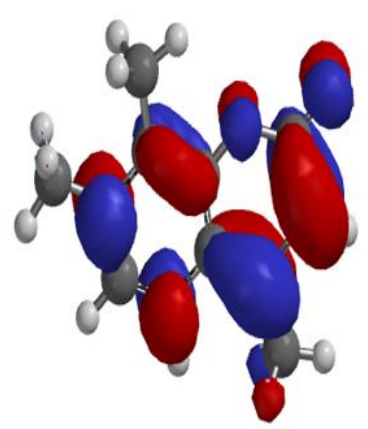

(c)

Figure 8. (a) Optimized structure of d, (b) HOMO map of d, and (c) LUMO map of d.
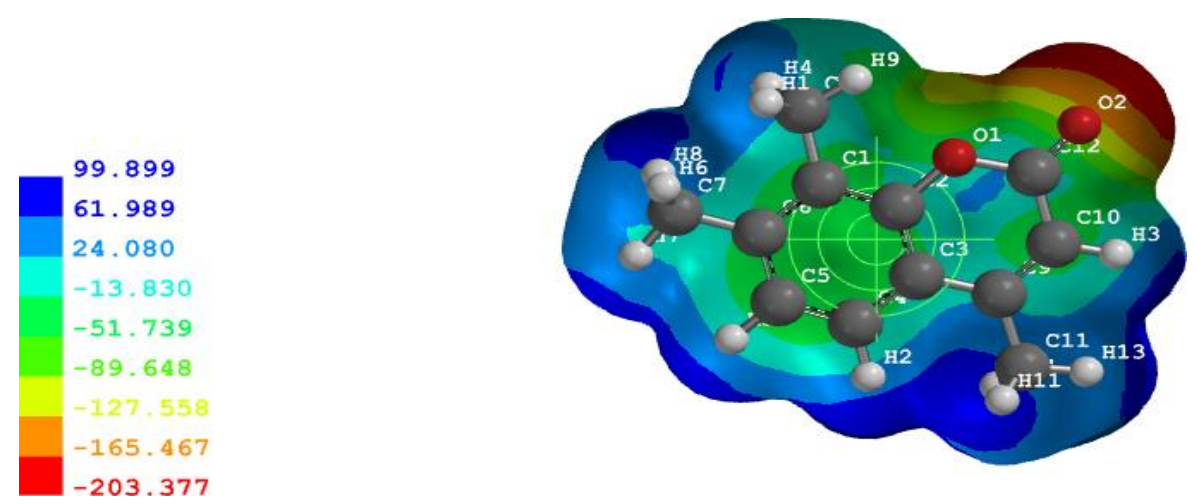

Figure 9. Electrostatic potential map of d.

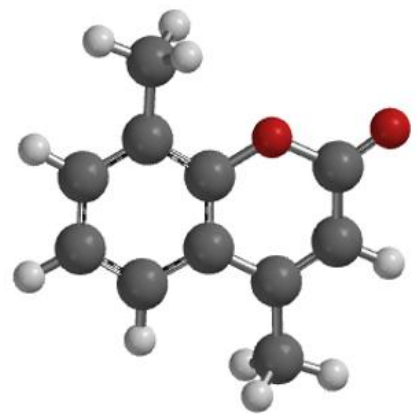

(a)

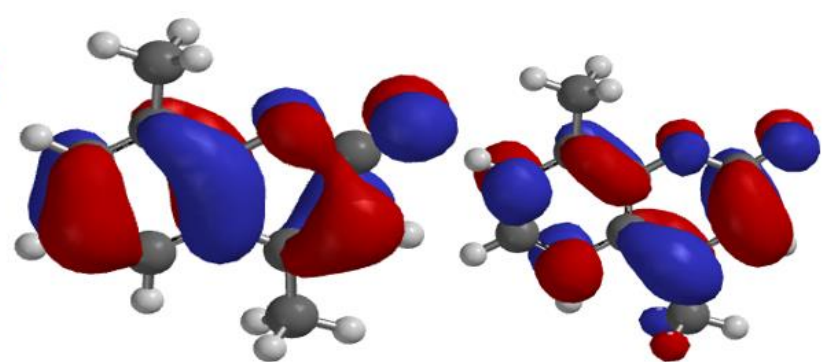

(c)

Figure 10. (a) Optimized structure of e, (b) HOMO map of e, and (c) LUMO map of e. 


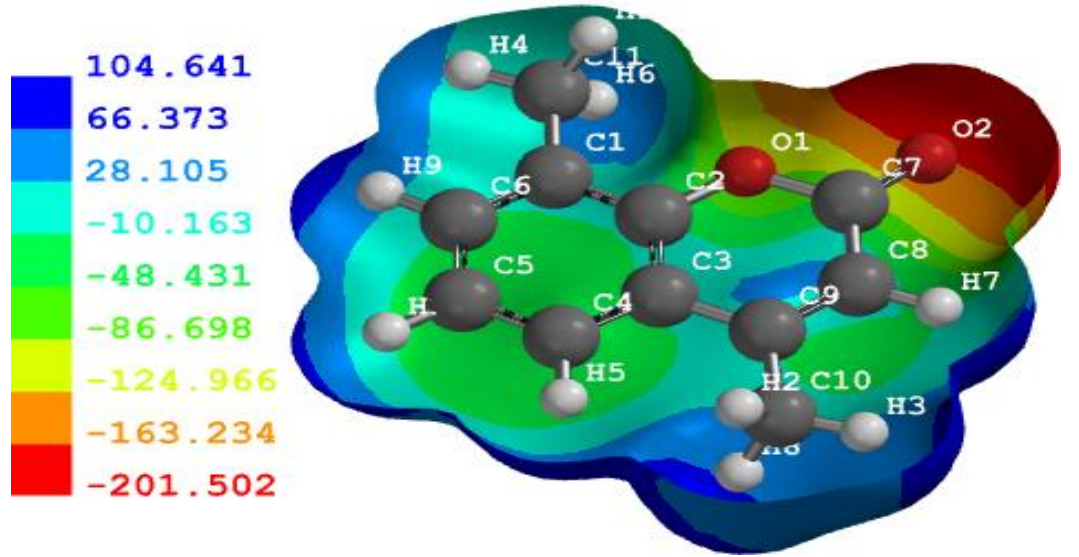

Figure 11. Electrostatic potential map of e.

The HOMO map of the corrosion inhibitors (Figures 2b, 4b, 6b, 8b, 10b, 12b, 14b, and $16 \mathrm{~b}$ ) is essentially delocalized over the benzopyran-2-one moiety and the attached substituents $\left(\mathrm{Cl}, \mathrm{Br}\right.$, and $\left.\mathrm{NH}_{2}\right)$ at position 6 excluding the methyl groups (at positions 4, 5, 7 and 8). This suggests that the benzopyran-2-one surface is electron-rich and may be involved in electron donation to the metal surface. Similarly, the LUMO plot of the compounds (Figures 2c, 4c, 6c, $8 \mathrm{c}, 10 \mathrm{c}, 12 \mathrm{c}, 14 \mathrm{c}$, and 16c) shows a delocalization of the lowest vacant molecular orbitals over the entire benzopyran-2-one moiety. This suggests that the low-lying vacant orbitals of the inhibitors could be available for back donation. Noteworthy is the fact that the substituents $(\mathrm{Cl}$, $\mathrm{Br}$, and $\mathrm{NH}_{2}$ ) at position 6 are not available for back donation (since they are excluded from LUMO distribution), but they may be majorly involved in electron donation.

Table 3. Selected calculated Fukui functions and Mulliken atomic charges of $b$.

\begin{tabular}{lcccccc}
\hline Atoms & $\mathbf{q}_{\mathbf{k}}(\mathbf{N}+\mathbf{1})$ & $\mathbf{\mathbf { q } _ { \mathbf { k } }}$ & $\mathbf{q}_{\mathbf{k}} \mathbf{( \mathbf { N } - \mathbf { 1 } )}$ & $\mathbf{f}_{\mathbf{K}}^{+}$ & $\mathbf{f}_{\mathbf{K}}{ }^{-}$ & $\Delta \mathbf{f k}^{\mathbf{2}}$ \\
\hline C1 & -0.279 & -0.243 & -0.216 & -0.036 & -0.027 & -0.009 \\
C2 & 0.322 & 0.322 & 0.38 & 0 & -0.058 & 0.058 \\
C3 & 0.03 & 0.035 & 0.043 & -0.005 & -0.008 & 0.003 \\
C4 & 0.081 & 0.112 & 0.123 & -0.031 & -0.011 & -0.02 \\
C5 & -0.207 & -0.207 & -0.182 & 0 & -0.025 & 0.025 \\
C6 & 0.183 & 0.202 & 0.217 & -0.019 & -0.015 & -0.004 \\
C7 & -0.522 & -0.532 & -0.546 & 0.01 & 0.014 & -0.004 \\
C8 & -0.525 & -0.541 & -0.549 & $\mathbf{0 . 0 1 6}$ & 0.008 & $\mathbf{0 . 0 0 8}$ \\
C9 & 0.11 & 0.189 & 0.197 & -0.079 & -0.008 & -0.071 \\
C10 & -0.323 & -0.293 & -0.247 & -0.03 & -0.046 & 0.016 \\
C11 & -0.526 & -0.537 & -0.553 & 0.011 & $\mathbf{0 . 0 1 6}$ & $-\mathbf{0 . 0 0 5}$ \\
C12 & 0.553 & 0.605 & 0.628 & -0.052 & -0.023 & -0.029 \\
O1 & -0.563 & -0.514 & -0.461 & -0.049 & -0.053 & 0.004 \\
O2 & -0.584 & -0.472 & -0.347 & -0.112 & -0.125 & 0.013 \\
\hline
\end{tabular}

Table 4. Selected calculated Fukui functions and Mulliken atomic charges of c.

\begin{tabular}{lcccccc}
\hline Atoms & $\mathbf{q}_{\mathbf{k}} \mathbf{( N + 1 )}$ & $\mathbf{q}_{\mathbf{k}}$ & $\mathbf{q}_{\mathbf{k}}(\mathbf{N}-\mathbf{1})$ & $\mathbf{f}_{\mathbf{K}}^{+}$ & $\mathbf{f}_{\mathbf{K}}^{-}$ & $\Delta \mathbf{f k}$ \\
\hline C1 & 0.109 & 0.133 & 0.157 & -0.024 & -0.024 & 0.181 \\
C2 & 0.226 & 0.241 & 0.32 & -0.015 & -0.079 & 0.335 \\
C3 & 0.052 & 0.044 & 0.059 & 0.008 & -0.015 & 0.051 \\
C4 & 0.082 & 0.108 & 0.105 & -0.026 & 0.003 & 0.131 \\
C5 & -0.186 & -0.185 & -0.128 & -0.001 & -0.057 & -0.127 \\
C6 & -0.22 & -0.184 & -0.159 & -0.036 & -0.025 & -0.123 \\
C7 & -0.502 & -0.513 & -0.527 & 0.011 & 0.014 & -0.538 \\
C8 & -0.522 & -0.537 & -0.55 & $\mathbf{0 . 0 1 5}$ & 0.013 & $-\mathbf{0 . 5 6 5}$ \\
C9 & 0.103 & 0.188 & 0.201 & -0.085 & -0.013 & 0.286 \\
C10 & -0.328 & -0.296 & -0.265 & -0.032 & -0.031 & -0.233 \\
C11 & -0.521 & -0.533 & -0.544 & 0.012 & 0.011 & -0.556 \\
C12 & 0.55 & 0.605 & 0.622 & -0.055 & -0.017 & 0.677 \\
O1 & -0.566 & -0.515 & -0.46 & -0.051 & -0.055 & -0.409 \\
O2 & -0.594 & -0.477 & -0.351 & -0.117 & -0.126 & -0.234 \\
\hline
\end{tabular}




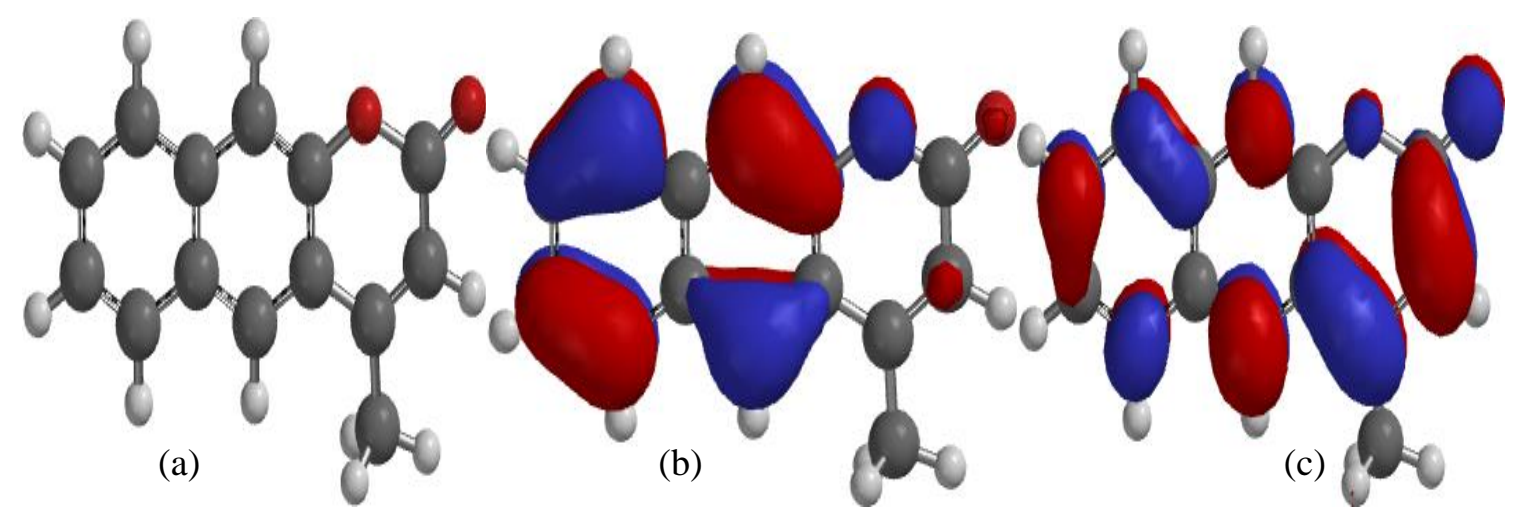

Figure 12. (a) Optimized structure of f, (b) HOMO map of f, and (c) LUMO map of $f$.
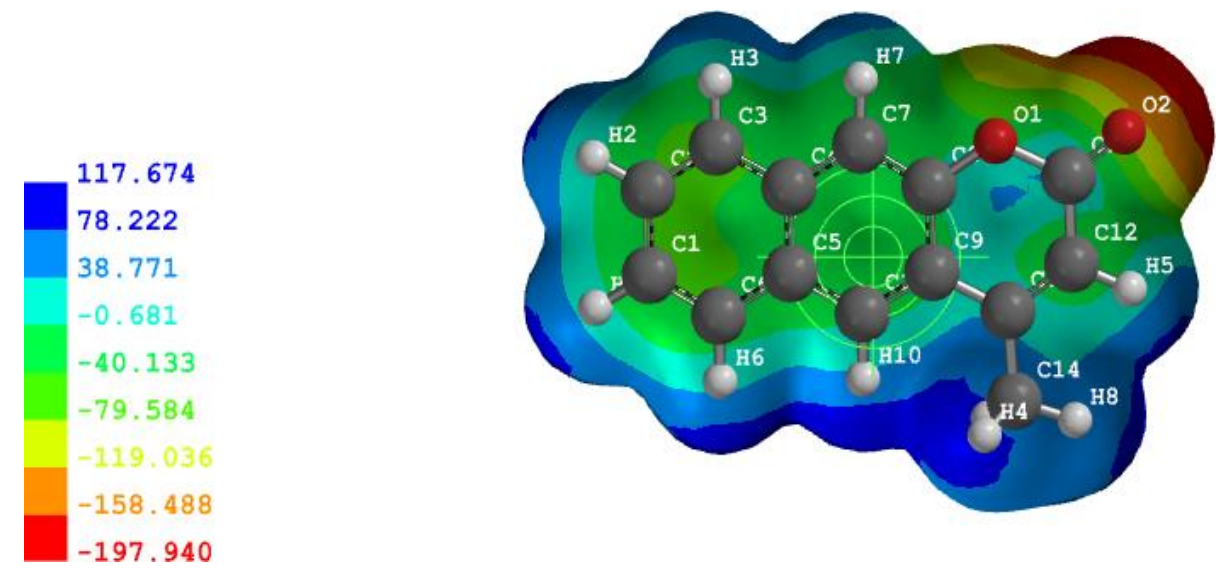

Figure 13. Electrostatic potential map of $f$.

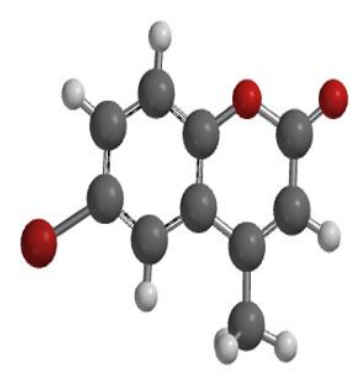

(a)

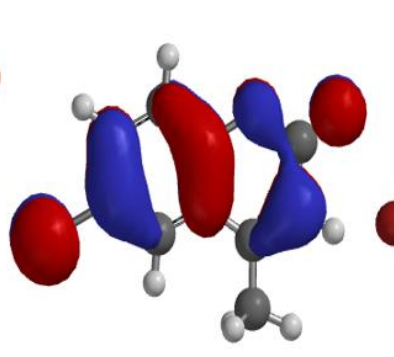

(b)

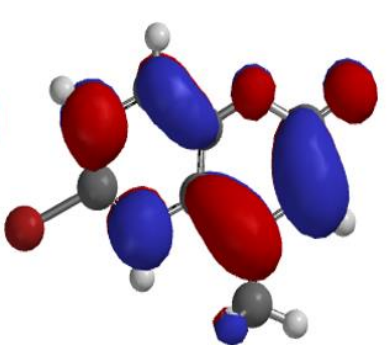

(c)

Figure 14. (a) Optimized structure of g, (b) HOMO map of g, and (c) LUMO map of g.
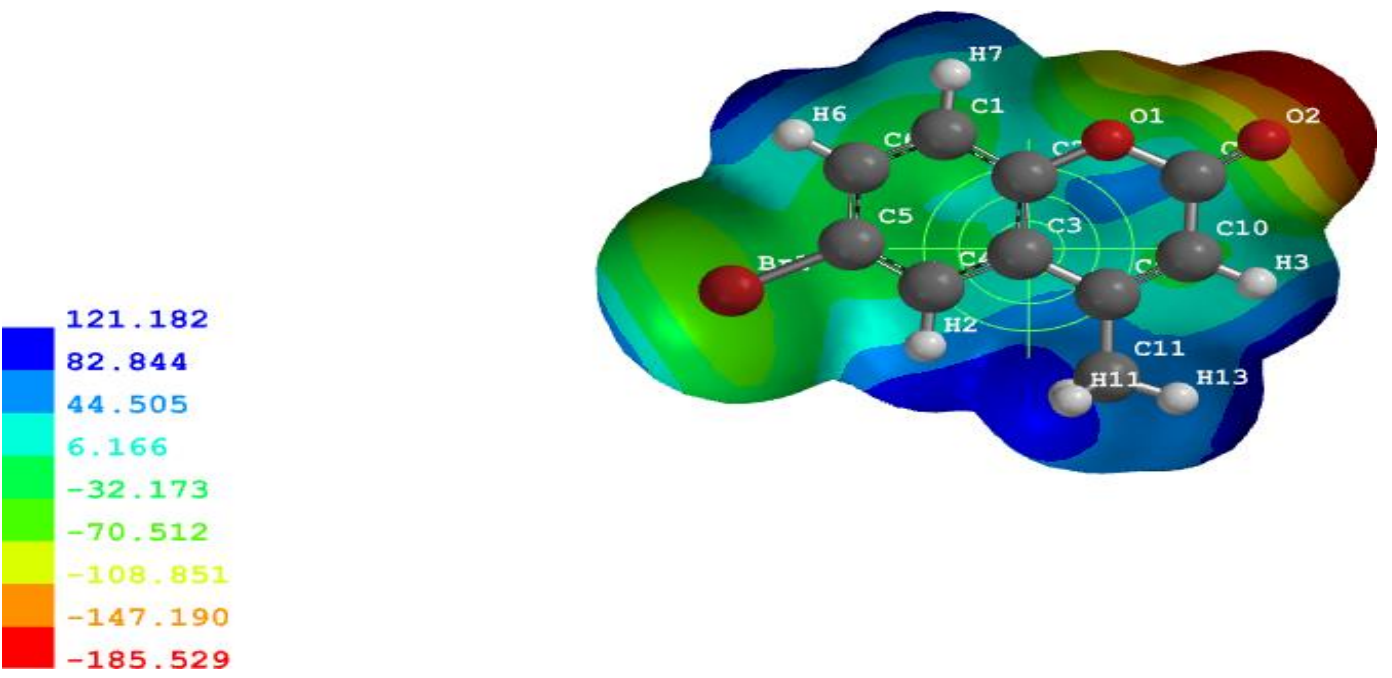

Figure 15. Electrostatic potential map of $\mathrm{g}$. 


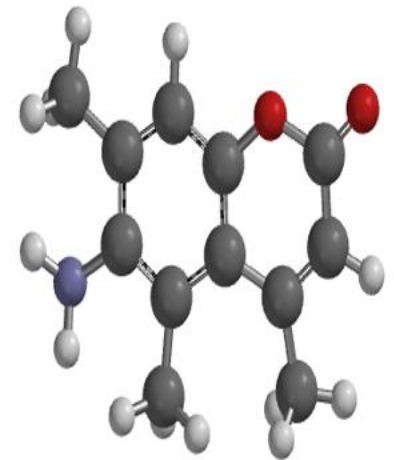

(a)

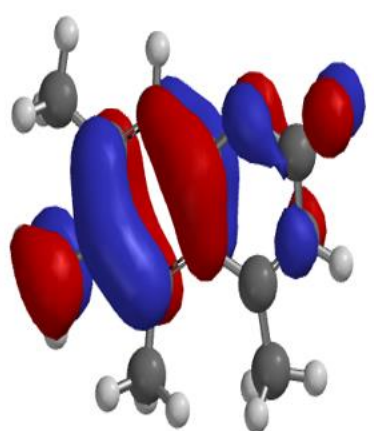

(b)

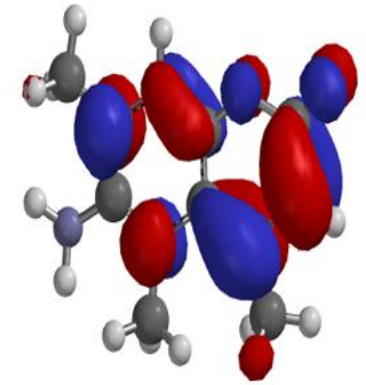

(c)

Figure 16. (a) Optimized structure of h, (b) HOMO map of h, and (c) LUMO map of h.
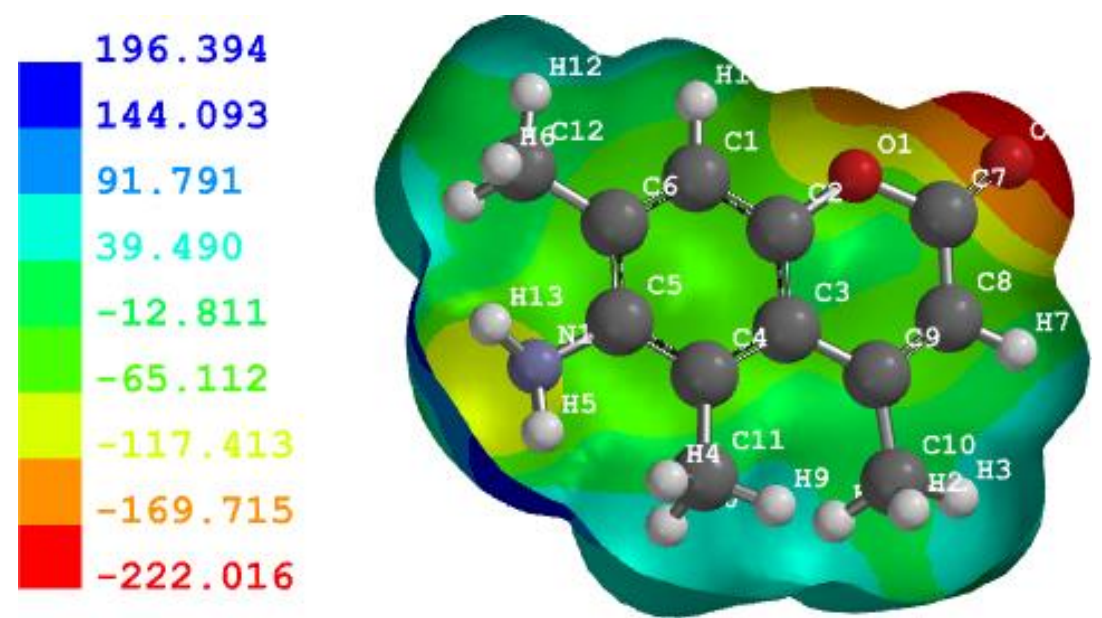

Figure 17. Electrostatic potential map of $h$.

\subsection{Corrosion inhibition and molecular properties.}

Quantum chemical parameters like ionization potential $(I)$, electron affinity $(A)$, global hardness $(\eta)$, global softness $(\sigma)$, electronegativity $(\chi)$, electrophilicity $(\omega)$ and the fraction of electron transferred $(\Delta N)$ describing the molecular properties of the corrosion inhibitors are also reported in Table 1. Their optimized structures are shown in Figures 2a, 4a, 6a, 8a, 10a, 12a, 14a and 16a. The ionization potential ( $I$ ) describes a corrosion inhibitor's tendency to release electrons (18). Compounds with low ionization potential possess good corrosion inhibition properties. Generally, the compounds present adequate ionization potential (6.02 $6.52 \mathrm{eV}$ ), which implies good electron-donating ability that may impede a corroding material's corrosion rate. Conversely, a corrosion inhibitor's high electron affinity is linked with its electron attracting potential and, consequently, effective corrosion inhibition potential.

The global hardness and softness are related to the chemical reactivity and kinetic stability of a system [25]. The $\eta$ follows a similar trend as the energy gap and is significantly low $(1.99-2.34 \mathrm{eV})$. The higher the global hardness, the less the kinetic instability and reactivity. Compounds $\mathrm{f}$ and $\mathrm{h}$ display least $\eta$, suggesting a good reactivity, molecular softness, and better anti-corrosion potential [26]. This mitigating corrosion potential of $\mathrm{f}$ and $\mathrm{h}$ is also corroborated by their high global softness.

Electronegativity $(\chi)$ is a quantum chemical descriptor that specifies the electron flow direction between a metal and the inhibitor until their chemical potentials are balanced $[5,10$, 21]. The inhibitors' electronegativity is within the range $3.46-4.28$, which suggests that all the compounds have a good potential of transferring an electron to the low-lying vacant orbital of 
the metal. The larger the difference in electronegativity of the iron and the corrosion inhibitor, the better the electron transfer potential and the better the corrosion inhibition potential. Compound h displays least $\chi$, and its $\Delta N$ approaches unity. This suggests that h possesses the best -donating ability, which could be attributed to $\pi$ - and nonbonding electrons and good molecular softness. On the other hand, compound f shows a comparable $\Delta N$ to that of $\mathrm{h}$, which could mainly be attributed to its $\pi$-electron richness, which may offer an adequate $\pi$ - $\pi$ stacking $[27,28]$, and coumarin heteroatom.

Electrophilicity is a measure of energy stabilization due to maximum electron flow between a donor and an acceptor. Lower $\omega$ implies that the compound will behave as a nucleophile [29]. The nucleophilic tendency of the corrosion inhibitor increases in the order $\mathrm{f}$ $<\mathrm{g}<\mathrm{b}<\mathrm{e}<\mathrm{c}<\mathrm{d}<\mathrm{a}<\mathrm{h}$. This suggests that $\mathrm{f}$ could act as the best electrophile while $\mathrm{h}$ is the best nucleophile. This implies compound $\mathrm{h}$ would present the greatest tendency of nucleophilic attack on the corroding material and, hence, behave as an excellent corrosion inhibitor.

Table 5. Selected calculated Fukui functions and Mulliken atomic charges of d.

\begin{tabular}{ccccccc}
\hline Atoms & $\mathrm{qk}_{\mathrm{k}}(\mathrm{N}+1)$ & $\mathrm{qk}_{\mathrm{k}}$ & $\mathrm{qk}_{\mathrm{k}}(\mathrm{N}-1)$ & $\mathrm{fK}^{+}$ & $\mathrm{fK}^{-}$ & $\Delta \mathrm{fk}$ \\
\hline $\mathrm{C} 1$ & 0.056 & 0.085 & 0.098 & -0.029 & -0.013 & 0.127 \\
$\mathrm{C} 2$ & 0.231 & 0.243 & 0.305 & -0.012 & -0.062 & 0.317 \\
$\mathrm{C} 3$ & 0.111 & 0.102 & 0.113 & 0.009 & -0.011 & 0.104 \\
$\mathrm{C} 4$ & -0.247 & -0.21 & -0.181 & -0.037 & -0.029 & -0.144 \\
$\mathrm{C} 5$ & -0.189 & -0.181 & -0.134 & -0.008 & -0.047 & -0.126 \\
C6 & 0.115 & 0.123 & 0.131 & -0.008 & -0.008 & 0.139 \\
C7 & -0.526 & -0.535 & -0.551 & 0.009 & $\mathbf{0 . 0 1 6}$ & $\mathbf{- 0 . 5 6}$ \\
C8 & -0.532 & -0.537 & -0.54 & 0.005 & 0.003 & -0.545 \\
C9 & 0.121 & 0.199 & 0.198 & -0.078 & 0.001 & 0.276 \\
C10 & -0.331 & -0.304 & -0.238 & -0.027 & -0.066 & -0.211 \\
C11 & -0.524 & -0.536 & -0.548 & $\mathbf{0 . 0 1 2}$ & 0.012 & $\mathbf{- 0 . 5 6}$ \\
C12 & 0.549 & 0.606 & 0.636 & -0.057 & -0.03 & 0.693 \\
O1 & -0.575 & -0.525 & -0.474 & -0.05 & -0.051 & -0.424 \\
O2 & -0.591 & -0.475 & -0.343 & -0.116 & -0.132 & -0.227 \\
\hline
\end{tabular}

Table 6. Selected calculated Fukui functions and Mulliken atomic charges of e.

\begin{tabular}{|c|c|c|c|c|c|c|}
\hline Atoms & $\mathrm{q}_{\mathrm{k}}(\mathrm{N}+\mathbf{1})$ & $\mathbf{q}_{\mathrm{k}}$ & $q_{k}(N-1)$ & $\mathbf{f K}^{+}$ & $\mathrm{f}_{\mathrm{K}^{-}}$ & $\Delta \mathbf{f k}$ \\
\hline $\mathrm{C} 1$ & 0.104 & 0.131 & 0.153 & -0.027 & -0.022 & 0.18 \\
\hline $\mathrm{C} 2$ & 0.232 & 0.245 & 0.32 & -0.013 & -0.075 & 0.333 \\
\hline $\mathrm{C} 3$ & 0.107 & 0.098 & 0.11 & 0.009 & -0.012 & 0.101 \\
\hline $\mathrm{C} 4$ & -0.246 & -0.211 & -0.191 & -0.035 & -0.02 & -0.156 \\
\hline C5 & -0.125 & -0.124 & -0.082 & -0.001 & -0.042 & -0.081 \\
\hline C6 & -0.221 & -0.189 & -0.166 & -0.032 & -0.023 & -0.134 \\
\hline $\mathrm{C} 8$ & -0.503 & -0.514 & -0.525 & 0.011 & 0.011 & -0.536 \\
\hline C9 & 0.12 & 0.199 & 0.207 & -0.079 & -0.008 & 0.286 \\
\hline $\mathrm{C} 10$ & -0.329 & -0.301 & -0.252 & -0.028 & -0.049 & -0.224 \\
\hline $\mathrm{C} 11$ & -0.524 & -0.537 & -0.548 & 0.013 & 0.011 & -0.561 \\
\hline $\mathrm{C} 12$ & 0.547 & 0.606 & 0.63 & -0.059 & -0.024 & 0.689 \\
\hline O1 & -0.571 & -0.518 & -0.456 & -0.053 & -0.062 & -0.403 \\
\hline $\mathrm{O} 2$ & -0.593 & -0.473 & -0.334 & -0.12 & -0.139 & -0.214 \\
\hline
\end{tabular}

\subsection{Corrosion inhibition and electrostatic potential map.}

The electrostatic potential map shows an overview of the charge density of the molecule. The greatest negative electrostatic potential is concentrated around the lactone carbonyl group (red color legend), as shown in Figures 3, 5, 7, 9, 11, 13, 15, and 17. This suggests that the carbonyl group is electron-rich (which may be attributed to its electronwithdrawing effect) and is most susceptible to an electrophilic attack. The regions with $\mathrm{CH}_{3}$ and $\mathrm{NH}_{2}$ groups show positive electrostatic potential (blue color legend), which implies that they are electron deficient and are susceptible to nucleophilic attack. The asymmetric charge 
distribution on the inhibitors indicates that each compound possesses reactive adsorption sites for bonding and back-bonding with the metal surface.

\subsection{Fukui indices and Mulliken charge distribution.}

The partition of charges on the corrosion inhibitors gives a good idea of the possible reactive sites on the benzopyran-2-ones. Mulliken charge analysis performed on the neutral, anionic, and cationic species of the benzopyran-2-ones are reported in Tables $2-9$ (excluding the hydrogen atoms) from which the Fukui indices were determined. The heteroatoms, especially the coumarin oxygen atoms, $\mathrm{Cl}, \mathrm{Br}$, and amine nitrogen, display negative Mulliken charges, suggesting that they are probable sites for nucleophilic attack and adsorption on a metal surface.

Table 7. Selected calculated Fukui functions and Mulliken atomic charges of $\mathrm{f}$.

\begin{tabular}{lcccccc}
\hline Atoms & $\mathbf{q}_{\mathbf{k}} \mathbf{( N + 1 )}$ & $\mathbf{q} \mathbf{k}$ & $\mathbf{q} \mathbf{k}(\mathbf{N}-\mathbf{1})$ & $\mathbf{f k}^{+}$ & $\mathbf{f k}^{-}$ & $\Delta \mathbf{f k}$ \\
\hline C1 & -0.102 & -0.139 & -0.142 & 0.037 & 0.003 & -0.179 \\
C2 & -0.115 & -0.133 & -0.154 & 0.018 & 0.021 & -0.172 \\
C3 & -0.146 & -0.192 & -0.225 & 0.046 & 0.033 & -0.271 \\
C4 & 0.146 & 0.146 & 0.151 & 0 & -0.005 & 0.151 \\
C5 & 0.163 & 0.154 & 0.173 & 0.009 & -0.019 & 0.164 \\
C6 & -0.17 & -0.187 & -0.222 & 0.017 & 0.035 & -0.239 \\
C7 & -0.208 & -0.267 & -0.309 & 0.059 & 0.042 & -0.368 \\
C8 & 0.367 & 0.323 & 0.323 & 0.044 & 0 & 0.279 \\
C9 & 0.093 & 0.096 & 0.102 & -0.003 & -0.006 & 0.105 \\
C10 & -0.245 & -0.304 & -0.358 & 0.059 & 0.054 & -0.417 \\
C11 & 0.215 & 0.208 & 0.14 & 0.007 & 0.068 & 0.133 \\
C12 & -0.279 & -0.307 & -0.33 & 0.028 & 0.023 & -0.358 \\
C13 & 0.619 & 0.611 & 0.561 & 0.008 & 0.05 & 0.553 \\
C14 & -0.547 & -0.536 & -0.524 & -0.011 & -0.012 & -0.513 \\
O1 & -0.487 & -0.522 & -0.557 & 0.035 & 0.035 & -0.592 \\
O2 & -0.374 & -0.468 & -0.572 & $\mathbf{0 . 0 9 4}$ & $\mathbf{0 . 1 0 4}$ & $\mathbf{- 0 . 6 6 6}$ \\
\hline
\end{tabular}

The Fukui indices $\left(\mathrm{f}_{\mathrm{k}}{ }^{+}\right.$and $\left.\mathrm{f}_{\mathrm{k}}{ }^{-}\right)$describe the local reactivity of atoms in the system. For a better description of the reactive sites for nucleophilic and electrophilic attacks, the dual descriptor $\left(\Delta \mathrm{f}_{\mathrm{k}}\right)$ provides a clearer view of each atom. When the Fukui index for the nucleophilic attack is greater than that of electrophilic attack $\left(\Delta f_{k}>0\right)$, the reactive site is adjudged susceptible to electrophilic attack (that is, the atom is a nucleophilic center), and vice versa $[15,30]$.

Table 2 shows the Fukui indices for the inhibitor a. The methyl carbon (C8) presents the highest $\mathrm{f}_{\mathrm{k}}{ }^{+}$, which suggests that it is a good nucleophilic center, while the methyl carbon (C7) shows the highest $\mathrm{f}_{\mathrm{k}}{ }^{-}$and consequently, is a good electrophilic center. This observation is in agreement with the values of the dual Fukui indices. Similar results are obtained for $\mathrm{c}$ and $\mathrm{d}$ (the isomeric forms of a) in Tables 4 and 5.

The methyl carbon at position $4(\mathrm{C} 11)$ displays a high $\mathrm{fk}_{\mathrm{k}}{ }^{+}$and $\mathrm{f}_{\mathrm{k}}{ }^{-}$in compound $\mathrm{g}$ (Table 8). This implies that the site is susceptible to nucleophilic and electrophilic attacks. However, $\Delta \mathrm{f}_{\mathrm{k}}$ value of -0.561 suggests that the atom will be a better electrophilic site. Similarly, the atom $\mathrm{C} 11$ of compound $\mathrm{b}$ (chloro-substituted derivative) has the highest $\mathrm{f}_{\mathrm{k}}{ }^{-}$and its $\Delta \mathrm{f}_{\mathrm{k}}$ value (Table 3 ) suggests that it is a good electrophilic site (Table 3). However, the carbon atom at position 5 (C8) for the corrosion inhibitor $b$ presents the highest $\mathrm{f}_{\mathrm{k}}{ }^{+}$and positive $\Delta \mathrm{f}_{\mathrm{k}}$, suggesting that it would be a reactive site for nucleophilic attack on a metal surface. Compound $\mathrm{h}$ shows comparable reactive sites for corrosion inhibition as those of $\mathrm{b}$ and $\mathrm{g}$. The methyl carbons at positions 4, 5, and 7 (C10, C11, and C12) are effective sites for electrophilic and nucleophilic attacks on a metal surface as obtained from the $\mathrm{f}_{\mathrm{k}}{ }^{+}$and $\mathrm{f}_{\mathrm{k}}{ }^{-}$values (Table 9 ). 
Table 6 shows the Fukui indices of compound e. The nucleophilic attack index $\left(\mathrm{f}_{\mathrm{k}}{ }^{+}\right)$ identifies C11 (methyl carbon at position 8) as the effective nucleophilic site. This same atom (C11) is considered an effective electrophilic center due to its high $\mathrm{f}_{\mathrm{k}}{ }^{-}$value. Nevertheless, the dual Fukui index $\left(\Delta \mathrm{f}_{\mathrm{k}}=-0.561\right)$ preferably depicts the atom, $\mathrm{C} 11$, as an electrophilic site.

The carbonyl oxygen $(\mathrm{O} 2)$ of the benzochromen-2-one (compound $\mathrm{f}$ ) exhibits high $\mathrm{f}_{\mathrm{k}}{ }^{+}$ and $\mathrm{f}_{\mathrm{k}}{ }^{-}$values, which implies that it may be a good nucleophilic and electrophilic site (Table 7). The highly negative $\Delta \mathrm{f}_{\mathrm{k}}$ value of $\mathrm{O} 2$, however, suggests that the atom is preferably an electrophilic center. In the same vein, the highly positive $\Delta f_{k}$ value of $\mathrm{C} 13$ may imply that the atom is an effective site for nucleophilic attack.

Table 8. Selected calculated Fukui functions and Mulliken atomic charges of $\mathrm{g}$.

\begin{tabular}{lcccccc}
\hline Atoms & $\mathbf{q}_{\mathbf{k}}(\mathbf{N}+\mathbf{1})$ & $\mathbf{q}$ & $\mathbf{q}_{\mathbf{k}}(\mathbf{N}-\mathbf{1})$ & $\mathbf{f}_{\mathbf{K}}^{+}$ & $\mathbf{f}_{\mathbf{K}}^{-}$ & $\Delta \mathbf{f k}$ \\
\hline C1 & -0.21 & -0.166 & -0.132 & -0.044 & -0.034 & -0.088 \\
C2 & 0.318 & 0.317 & 0.37 & 0.001 & -0.053 & 0.369 \\
C3 & 0.086 & 0.089 & 0.102 & -0.003 & -0.013 & 0.105 \\
C4 & -0.264 & -0.227 & -0.206 & -0.037 & -0.021 & -0.169 \\
C5 & 0.017 & 0.013 & 0.023 & 0.004 & -0.01 & 0.019 \\
C6 & -0.186 & -0.148 & -0.119 & -0.038 & -0.029 & -0.081 \\
C9 & 0.13 & 0.205 & 0.212 & -0.075 & -0.007 & 0.287 \\
C10 & -0.329 & -0.298 & -0.254 & -0.031 & -0.044 & -0.223 \\
C11 & -0.527 & -0.539 & -0.549 & $\mathbf{0 . 0 1 2}$ & $\mathbf{0 . 0 1}$ & $-\mathbf{0 . 5 6 1}$ \\
C12 & 0.555 & 0.608 & 0.63 & -0.053 & -0.022 & 0.683 \\
O1 & -0.566 & -0.515 & -0.46 & -0.051 & -0.055 & -0.409 \\
O2 & -0.58 & -0.464 & -0.338 & -0.116 & -0.126 & -0.222 \\
Br1 & -0.202 & -0.069 & 0.17 & -0.133 & -0.239 & 0.303 \\
\hline
\end{tabular}

Table 9. Selected calculated Fukui functions and Mulliken atomic charges of $h$.

\begin{tabular}{lllllll}
\hline Atoms & $\mathbf{q}_{\mathbf{k}}(\mathbf{N}+\mathbf{1})$ & $\mathbf{q}_{\mathbf{k}}$ & $\mathbf{q}_{\mathbf{k}}(\mathbf{N}-\mathbf{1})$ & $\mathbf{f}_{\mathbf{+}}{ }^{+}$ & $\mathbf{f}_{\mathbf{K}}^{-}$ & $\Delta \mathbf{f k}^{-}$ \\
\hline C1 & -0.291 & -0.265 & -0.244 & -0.026 & -0.021 & -0.218 \\
C2 & 0.313 & 0.314 & 0.375 & -0.001 & -0.061 & 0.376 \\
C3 & 0.022 & 0.013 & 0.017 & 0.009 & -0.004 & 0.008 \\
C4 & 0.055 & 0.09 & 0.107 & -0.035 & -0.017 & 0.142 \\
C5 & 0.136 & 0.183 & 0.281 & -0.047 & -0.098 & 0.328 \\
C6 & 0.16 & 0.186 & 0.208 & -0.026 & -0.022 & 0.234 \\
C7 & 0.55 & 0.602 & 0.62 & -0.052 & -0.018 & 0.672 \\
C8 & -0.326 & -0.298 & -0.271 & -0.028 & -0.027 & -0.243 \\
C9 & 0.109 & 0.193 & 0.205 & -0.084 & -0.012 & 0.289 \\
C10 & -0.529 & -0.546 & -0.558 & $\mathbf{0 . 0 1 7}$ & 0.012 & $\mathbf{- 0 . 5 7 5}$ \\
C11 & -0.549 & -0.565 & -0.586 & 0.016 & $\mathbf{0 . 0 2 1}$ & $-\mathbf{0 . 6 0 2}$ \\
C12 & -0.545 & -0.558 & -0.579 & 0.013 & 0.021 & -0.592 \\
O1 & -0.567 & -0.517 & -0.48 & -0.05 & -0.037 & -0.43 \\
O2 & -0.595 & -0.484 & -0.377 & -0.111 & -0.107 & -0.266 \\
N1 & -0.799 & -0.802 & -0.759 & 0.003 & -0.043 & -0.762 \\
\hline
\end{tabular}

The Mulliken charge distribution and the Fukui indices reveal that the adsorption of an inhibitor on a metal surface is not only via the heteroatoms like $\mathrm{O}, \mathrm{Cl}, \mathrm{Br}$, and $\mathrm{N}$. The contribution of carbon atoms as nucleophilic and electrophilic centers ensures effective interaction between a metal surface and the inhibitor and isolates the material from corroding environment. This interaction, consequently, will impede the rate of corrosion.

\section{Conclusions}

The corrosion inhibition potentials of eight benzopyran-2-ones (a-h) have been investigated using Density Functional Theory. The low energy gap and global hardness, and high molecular softness of the compounds suggest that the compounds are good corrosion inhibitors. However, compounds f and h exhibit remarkably low energy gaps with relatively high global softness, which implies that these inhibitors are reactive and kinetically unstable, 
with excellent anti-corrosion potentials. Also, the presence of an electron-donating amino group of compound h could be responsible for its low bandgap and high corrosion inhibition potential. The local reactive sites of interaction with the metal surface are the heteroatoms (nitrogen, bromine, chlorine, and oxygen) and the carbon atoms (especially the methyl groups).

\section{Funding}

This research received no external funding.

\section{Acknowledgments}

This research has no acknowledgment.

\section{Conflicts of Interest}

The authors declare no conflict of interest.

\section{References}

1. Verma, C.; Quraishi, M.A.; Ebenso, E.E. Microwave and ultrasound irradiations for the synthesis of environmentally sustainable corrosion inhibitors: An overview. Sustainable Chemistry and Pharmacy 2018, 10, 134-147, https://doi.org/10.1016/j.scp.2018.11.001.

2. Obot, I.B.; Obi-Egbedi, N.O.; Umoren, S.A. Antifungal drugs as corrosion inhibitors for aluminium in $0.1 \mathrm{M}$ HCl. Corrosion Science 2009, 51, 1868-1875, https://dx.doi.org/10.1016/j.corsci.2009.05.017.

3. Oyeneyin, O.; Obadawo, B.S; Ojo, F.K.; Akerele, D.D.; Akintemi, E.O.; Ejelonu, B.C.; Ipinloju, N. Experimental and Theoretical Study on the Corrosion Inhibitive Potentials of Schiff Base of Aniline and Salicyaldehyde on mild steel in $0.5 \mathrm{M} \mathrm{HCl}$ 2020, 2, 197-208, https://dx.doi.org/10.33945/SAMI/AJCB.2020.4.4.

4. Amoko, J.S.; Akinyele, O.F.; Oyeneyin, O.E.; Olayanju, D.; Aboluwoye, C.O. Experimental and Theoretical Investigation of Corrosion Inhibitive Potentials of (E)-4-hydroxy-3-[(2,4,6tribromophenyl)diazenyl]benzaldehyde on Mild Steel in Acidic Media. Physical Chemistry Research 2020, 8, 399-416, https://dx.doi.org/10.22036/pcr.2020.217825.1725.

5. Ahmed, S.K.; Ali, W.B.; Khadom, A.A. Synthesis and investigations of heterocyclic compounds as corrosion inhibitors for mild steel in hydrochloric acid. International Journal of Industrial Chemistry 2019, 10, 159-173, https://doi.org/10.1007/s40090-019-0181-8.

6. Rbaa, M.; Lakhrissi, B. Novel oxazole and imidazole based on 8-hydroxyquinoline as a corrosion inhibition of mild steel in $\mathrm{HCl}$ solution: Insights from experimental and computational studies. Surfaces and Interfaces 2019, 15, 43-59, https://doi.org/10.1016/j.surfin.2019.01.010.

7. Boughoues, Y.; Benamira, M.; Messaadia, L.; Ribouh, N. Adsorption and corrosion inhibition performance of some environmental friendly organic inhibitors for mild steel in $\mathrm{HCl}$ solution via experimental and theoretical study. Colloids and Surfaces A: Physicochemical and Engineering Aspects 2020, 593, https://doi.org/10.1016/j.colsurfa.2020.124610.

8. Fitoz, A.; Nazır, H.; Özgür, M.; Emregül, E.; Emregül, K.C. An experimental and theoretical approach towards understanding the inhibitive behavior of a nitrile substituted coumarin compound as an effective acidic media inhibitor. Corrosion Science 2018, 133, 451-464, https://doi.org/10.1016/j.corsci.2017.10.004.

9. Venugopala, K.N.; Rashmi, V.; Odhav, B. Review on Natural Coumarin Lead Compounds for Their Pharmacological Activity. BioMed Research International 2013, 2013, https://doi.org/10.1155/2013/963248.

10. Lira, S.P.d.; Seleghim, M.H.R.; Williams, D.E.; Marion, F.; Hamill, P.; Jean, F.; Andersen, R.J.; Hajdu, E.; Berlinck, R.G.S. A SARS-coronovirus 3CL protease inhibitor isolated from the marine sponge Axinella cf. corrugata: structure elucidation and synthesis. Journal of the Brazilian Chemical Society 2007, 18, 440-443, https://doi.org/10.1590/S0103-50532007000200030.

11. Annunziata, F.; Pinna, C.; Dallavalle, S.; Tamborini, L.; Pinto, A. An Overview of Coumarin as a Versatile and Readily Accessible Scaffold with Broad-Ranging Biological Activities. International Journal of Molecular Sciences 2020, 21, 1-83, https://doi.org/10.3390/ijms21134618.

12. Katariya A.P.; Deshmukh S.U.; Tekale S.U.; Katariya M.V. Amberlite IR-120 Catalyzed Green and Efficient One-Pot Synthesis of Benzylpyrazolyl Coumarin in Aqueous Medium. Lett Appl NanoBioScience 2021, 10, 2525-34.

13. Basavarajappa, K.V.; Arthoba Nayaka, Y.; Purushothama, H.T.; Yathisha, R.O.; Vinay, M.M.; Rudresha, B.J.; Manjunatha, K.B. Optical, electrochemical and current-voltage characteristics of novel coumarin based 
2,4-dinitrophenylhydrazone derivatives. Journal of Molecular Structure 2020, 1199, https://doi.org/10.1016/j.molstruc.2019.126946.

14. Wang, Z.-S.; Hara, K.; Dan-oh, Y.; Kasada, C.; Shinpo, A.; Suga, S.; Arakawa, H.; Sugihara, H. Photophysical and (Photo)electrochemical Properties of a Coumarin Dye. The Journal of Physical Chemistry B 2005, 109, 3907-3914, https://doi.org/10.1021/jp044851v.

15. Odewole, O.A.; Ibeji, C.U.; Oluwasola, H.O.; Oyeneyin, O.E.; Akpomie, K.G.; Ugwu, C.M.; Ugwu, C.G.; Bakare, T.E. Synthesis and anti-corrosive potential of Schiff bases derived 4-nitrocinnamaldehyde for mild steel in $\mathrm{HCl}$ medium: Experimental and DFT studies. Journal of Molecular Structure 2021, 1223, https://doi.org/10.1016/j.molstruc.2020.129214.

16. Gulati, S.; Singh, R.; Sangwan, S.; Punia, J.; Mehta, S. A simple and efficient synthesis of substituted 2H1-benzopyran-2-ones using natural acids and their bio evaluation. Arabian Journal of Chemistry 2020, 13, 7558-7571, https://doi.org/10.1016/j.arabjc.2020.08.030.

17. Becke, A.D. Density-functional thermochemistry. III. The role of exact exchange. The Journal of Chemical Physics 1993, 98, 5648-5652, https://doi.org/10.1063/1.464913.

18. Jensen, F. Polarization consistent basis sets: Principles. The Journal of Chemical Physics 2001, 115, 91139125, https://doi.org/10.1063/1.1413524.

19. SPARTAN 14', build 1.01. Irvine (CA); 2014.

20. Yang, W.; Parr, R.G. Hardness, softness, and the fukui function in the electronic theory of metals and catalysis. Proc Natl Acad Sci USA 1985, 82, 6723-6, https://doi.org/10.1073/pnas.82.20.6723.

21. Hu, J.; Zeng, D.; Zhang, Z.; Shi, T.; Song, G.-L.; Guo, X. 2-Hydroxy-4-methoxy-acetophenone as an environment-friendly corrosion inhibitor for AZ91D magnesium alloy. Corrosion Science 2013, 74, 35-43, https://doi.org/10.1016/j.corsci.2013.04.005.

22. Boughoues, Y.; Benamira, M.; Messaadia, L.; Bouider, N.; Abdelaziz, S. Experimental and theoretical investigations of four amine derivatives as effective corrosion inhibitors for mild steel in $\mathrm{HCl}$ medium. RSC Advances 2020, 10, 24145-24158, https://doi.org/10.1039/D0RA03560B.

23. Obi-Egbedi, N.O; Obot, I.B. Inhibitive properties, thermodynamic and quantum chemical studies of alloxazine on mild steel corrosion in $\mathrm{H}_{2} \mathrm{SO}_{4}$. Corrosion Science 2011, 53, 263-275, https://doi.org/10.1016/j.corsci.2010.09.020.

24. Sharma, K.; Melavanki, R.; Patil, S.S.; Kusanur, R.; Patil, N.R.; Shelar, V.M. Spectroscopic behavior, FMO, NLO and NBO analysis of two novel aryl boronic acid derivatives: Experimental and theoretical insights. Journal of Molecular Structure 2019, 1181, 474-487, https://doi.org/10.1016/j.molstruc.2018.12.086.

25. Guo, L.; Ren, X.; Zhou, Y.; Xu, S.; Gong, Y.; Zhang, S. Theoretical evaluation of the corrosion inhibition performance of 1,3-thiazole and its amino derivatives. Arabian Journal of Chemistry 2017, 10, 121-130, http://dx.doi.org/10.1016/j.arabjc.2015.01.005.

26. Ojo, N.D.; Krause, R.W.; Obi-Egbedi, N.O. Electronic and nonlinear optical properties of 3-(((2-substituted4-nitrophenyl)imino)methyl)phenol. Computational and Theoretical Chemistry 2020, 1192, 1-8, https://doi.org/10.1016/j.comptc.

27. Achadu, O.J.; Nyokong, T. Graphene quantum dots decorated with maleimide and zinc tetramaleimidophthalocyanine: Application in the design of "OFF-ON" fluorescence sensors for biothiols. Talanta 2017, 166, 15-26, https://doi.org/10.1016/j.talanta.2017.01.031.

28. Ramírez-García, G.; Oluwole, D.O.; Nxele, S.R.; d’Orlyé, F.; Nyokong, T.; Bedioui, F.; Varenne, A. Characterization of phthalocyanine functionalized quantum dots by dynamic light scattering, laser Doppler, and capillary electrophoresis. Analytical and Bioanalytical Chemistry 2017, 409, 1707-1715, https://doi.org/10.1007/s00216-016-0120-x.

29. Justin, P.; Devi, R.N.; Anitha, K. Vibrational studies, quantum chemical calculations, and molecular modelling of ferrous fumarate. Canadian Journal of Physics 2018, 97, 308-316, https://doi.org/10.1139/cjp2017-0216.

30. Khemalapure, S.S.; Katti, V.S.; Hiremath, C.S.; Hiremath, S.M.; Basanagouda, M.; Radder, S.B. Spectroscopic (FT-IR, FT-Raman, NMR and UV-Vis), ELF, LOL, NBO, and Fukui function investigations on (5-bromo-benzofuran-3-yl)-acetic acid hydrazide (5BBAH): Experimental and theoretical approach. Journal of Molecular Structure 2019, 1196, 280-290, https://doi.org/10.1016/j.molstruc.2019.06.078. 